\title{
The Management in a Developing Country of Children with Type 1 Diabetes Mellitus at School: A Review of Attitude of Parents
}

\author{
Jaja Tamunopriye $\mathrm{e}^{1,2}$ \\ ${ }^{1}$ Department of Paediatrics and Child Health, Faculty of Clinical Sciences, College of Health Sciences, University of Port Harcourt, \\ Port Harcourt, Nigeria \\ ${ }^{2}$ Department of Paediatrics, University of Port Harcourt Teaching Hospital, Port Harcourt, Nigeria \\ Email: Tamunopriyej@yahoo.com
}

How to cite this paper: Tamunopriye, J. (2018) The Management in a Developing Country of Children with Type 1 Diabetes Mellitus at School: A Review of Attitude of Parents. International Journal of Clinical Medicine, 9, 327-334.

https://doi.org/10.4236/ijcm.2018.94028

Received: January 31, 2018

Accepted: April 27, 2018

Published: April 30, 2018

Copyright $\odot 2018$ by author and Scientific Research Publishing Inc. This work is licensed under the Creative Commons Attribution International License (CC BY 4.0).

http://creativecommons.org/licenses/by/4.0/

\begin{abstract}
Background: Optimal glycaemic control is essential in preventing diabetes related complications in children with diabetes. The school is an important component of care and support to achieve good outcome as children spend a considerable time in school. In some developed countries, there are guidelines and regulations on support and care of children with chronic diseases such as Type 1 Diabetes Mellitus (Type $1 \mathrm{DM}$ ). In most developing countries where these regulations are not in place, parents have an important role to play in encouraging optimal care for their wards while at school, which include informing school authority, submission of care plan in collaboration with the healthcare team and providing equipment necessary for care task at school. Aim and Objectives: The aim of this study was to review the attitudes of parents in a developing country towards management of their children with Type 1 Diabetes Mellitus (DM) at School. Methods: Parents of all children with Type $1 \mathrm{DM}$ seen at the endocrine unit of the University of Port Harcourt Teaching Hospital were invited to participate. Data were collected using a questionnaire. Information on bio data, details of care in school and challenges experienced were documented and $\mathrm{HbAlc}$ was done for all children. Results: The Parents of eighteen children and adolescents with Type 1 DM participated in the study. The age range of the children was between 5 and 17.3 years, mean age of $12.37 \pm 4.2$ years. Mean duration of DM $3.37 \pm 2.6$ years and mean $\mathrm{HbAlc}$ was $10.02 \% \pm 2.5 \%$. All children except one attended school as day students. Two parents (11.1\%) did not inform the school of child's diabetes. No parent gave a written plan of diabetes care/treatment of hypoglycaemia in school and 4 parents (22.2\%) did not make contact with school when child was in school. No child had a glucometers or took insulin
\end{abstract}


to school. Five parents $(27.8 \%)$ adjusted or omitted morning insulin dose to prevent hypoglycaemias in school. Fifteen $(83.3 \%)$ children were on twice daily insulin injections. Six children (33.3\%) are from high socioeconomic class. All responses were from mothers and 15 (83.3\%) of responders had at least secondary education. Conclusion: This study demonstrates poor attitude and deficiencies in care of children living with Type $1 \mathrm{DM}$ in school. There is need for education of parents and presentation of written plans for care of every child with Type $1 \mathrm{DM}$ in school.

\section{Keywords}

Childhood Diabetes, School Care, Parents

\section{Introduction}

Type 1 Diabetes Mellitus is a chronic debilitating disease and the commonest type of diabetes in children. It requires complete dependency on insulin for every day control and survival. The incidence of DM is increasing worldwide even in children [1]. In Sub-Saharan Africa, the International Diabetes Federation (IDF) estimates that 6100 new cases of Type 1 DM are diagnosed each year in children contributing to a total of 37,500 recorded cases in the whole region [2].

Complications of diabetes in children are prevented by maintaining optimal glycaemic control provided by optimal care at all times both at home and in school [3] [4]. Just like children without diabetes, most children with diabetes attend school and spend about 8 hours/day in school away from close monitoring and care offered by their families. It is therefore important that diabetes care is optimal both at home and when the child is in school.

Lack of awareness of child's condition by teachers could create misunderstanding and also erode the gains achieved with care at home. There have been reports of poor control and outcome in children with diabetes in most developing countries and several factors have been stated as reasons for this poor outcome amongst which are lack of insulin, lack of blood glucose monitoring and high cost of care [5] [6] [7]. The contribution to poor outcome based on care in schools have attracted little attention with no or lack of awareness of regulations on care for chronic disease management in most developing countries as obtains in most developed countries. Every child living with type 1 diabetes should have an individualized care plan while at school, this plan should be developed by the parents/guardian in collaboration with the health team and school [8]. The parents act in interfacing between the Health team and the school and provide all materials necessary for diabetes care in school such as blood glucose monitoring kits, insulin, Ketones strips, hypoglycaemia kits, food schedules and log books for charting events at school and contacts of parents and health team in case of emergencies. The care of children with Type 1 diabetes in schools therefore depends a great deal on knowledge and attitude of parents towards care in school. 
The aim of this study was to assess the attitude of parents in a developing country towards management of their children living with diabetes while in school.

\section{Methodology}

The study population consisted of all parents of children living with diabetes mellitus who attend the diabetes clinic at the University of Port Harcourt Teaching Hospital in the last five years. The hospital is the only tertiary hospital in the state and receives referrals on all subspecialties from other private and government hospitals from the state and neighbouring states. The diabetes clinic is run every Monday with the team on daily call.

Parents of all children with Type 1 DM seen at the Paediatric endocrine unit of the University of Port Harcourt Teaching Hospital were invited to participate. The diagnosis of Type 1 DM was based on the ISPAD clinical Practice consensus guideline [9]. Parents of children with type 2 DM, not receiving insulin and parents of children not yet in school were also excluded. The socioeconomic classification was determined based on criteria described by Oyedeji using occupation and educational qualification of parents or surrogates [10]. All parents included in report gave informed consent.

Data was collected over a three months period using a questionnaire. Information on bio data of child, parents and family was obtained. Details of care in school and challenges experienced during school related to diabetes care and communication between school and parents were documented. HbAlic was done for all children included by the investigators at no cost using the Bio-RAD in2it Analyzer (UK) making use of the Bio-RAD system test cartridge. Primary care givers completed the interviewer administered questionnaires.

Ethical clearance for the study was obtained from the ethics committee of the University of Port Harcourt Teaching Hospital.

Data was entered into excel sheet and analysed using SPSS version 20.0. Clinical characteristics were described using mean and standard deviation for continuous variables and percentages for ordinal variables. Comparison was done using $\mathrm{t}$-test and chi-squared test

\section{Result}

At the time of this study, there were 28 children on follow up in the unit with diabetes mellitus. Twenty five (89.3\%) had type $1 \mathrm{DM}$ and Three (10.7\%) had type 2 DM. Eighteen (72\%) parents who had children or adolescents with Type 1 DM completed the questionnaire over the study period and were analysed.

In $17(94.4 \%)$ cases the mothers completed the questionnaire. Six (33.3\%) families were of high socioeconomic class. All children attended private schools and all attended as day students except one adolescent. 15(83.3\%) of parents who completed the questionnaires were primary care givers and had minimum of secondary education. 
The age range of children of participating parents was between 5 and 17 years with a mean age of $12.18 \pm 1.7$ and mean duration of diabetes was $3.12 \pm 2.4$ years. Nine $(50 \%)$ were males. Fourteen $(77.8 \%)$ of the subjects were on twice daily insulin schedule. Clinical characteristics of the children and parents are as shown in Table 1. The response of parents to care of their child in school is shown in Table 2. The response was all from mothers. $88.9 \%$ of children did not take glucometers to school and $44.4 \%$ of parents never made contact with school to ascertain their child's welfare. However, $87.5 \%$ of children less than 10 years compared to $30 \%$ of those above 10years had their parents make contact with school.

\section{Discussion}

This study has looked at attitude of parents towards care of their children living

Table 1. Clinical characteristics of subjects with diabetes and participating parents.

\begin{tabular}{|c|c|c|c|c|}
\hline & All subjects & $<10$ years & $\geq 10$ years & $P$-value \\
\hline Number & 18 & 8 & 10 & \\
\hline Males & 9 & 6 & 3 & \\
\hline Females & 9 & 2 & 7 & \\
\hline Mean Age (SD) & $12.37 \pm 4.2$ & $7.98 \pm 1.61$ & $15.89 \pm 1.29$ & \\
\hline Age range & 5- 17.3 & & & \\
\hline \multicolumn{5}{|l|}{ Duration Diabetes } \\
\hline Mean \pm SD & $3.37 \pm 2.6$ yrs. & $2.35 \pm 1.3 \mathrm{yrs}$ & $4.19 \pm 3.17 \mathrm{yrs}$ & \\
\hline Range & $0.5-10.3$ yrs. & $0.5-4.0 \mathrm{yrs}$ & $1.0-10.3$ yrs. & \\
\hline Mean HbAlc (\%) & $10.02 \pm 2.5$ & $9.07 \pm 2.58$ & $10.69 \pm 2.39$ & 0.214 \\
\hline \multicolumn{5}{|l|}{ Subjects who had hypo in school } \\
\hline Yes & $8(44.4 \%)$ & $6(75 \%)$ & $2(20 \%)$ & \multirow{2}{*}{$0.020^{*}$} \\
\hline No & $10(55.6 \%)$ & $2(25 \%)$ & $8(80 \%)$ & \\
\hline $\begin{array}{l}\text { Subjects who had other Issues } \\
\text { in School }\end{array}$ & $11(61.1 \%)$ & $5(62.5 \%)$ & $6(60 \%)$ & \\
\hline $\begin{array}{l}\text { Subjects on more than twice insulin } \\
\text { shots/day }\end{array}$ & $2(22.2 \%)$ & $0(0 \%)$ & $2(20 \%)$ & \\
\hline \multicolumn{5}{|l|}{ Insulin Delivery methods } \\
\hline Syringes & $15(83.3)$ & & & \\
\hline Pen & $3(16.7)$ & & & \\
\hline Insulin Pump & $0(0.00)$ & & & \\
\hline \multicolumn{5}{|l|}{$\begin{array}{l}\text { Level of Education of } \\
\text { Participating parents }\end{array}$} \\
\hline Nil & $0(0.00)$ & & & \\
\hline Primary & $3(16.6)$ & & & \\
\hline Secondary & $7(38.9)$ & & & \\
\hline Tertiary & $8(44)$ & & & \\
\hline
\end{tabular}

${ }^{\star}$ Indicates statistically significant. 
Table 2. Questions on contribution to diabetes care by parents while their wards are in school stratified by age of child.

\begin{tabular}{cccc}
\hline Parents Response to Actions on School care? & $<10 y r s$ & $\geq 10$ yrs. & Total (\%) \\
\hline Did you Inform School about Child's DM? & 8 & & \\
Yes & V & $14(77.8)$ \\
No & 0 & 4 & $4(22.2)$
\end{tabular}

Did you give a written plan to school on the care of your child?

$\begin{array}{llll}\text { Yes } & 1 & 1 & 2(11.1) \\ \text { No } & 7 & 9 & 16(88.9)\end{array}$

Did you give written plan to treat hypoglycaemia in school?

$\begin{array}{lccc}\text { Yes } & 3 & 0 & 3(16.7) \\ \text { No } & 5 & 10 & 15(83.3)\end{array}$

Does your child take Glucometers and other care materials to school?

$\begin{array}{llll}\text { Yes } & 0 & 2 & 2(11.1) \\ \text { No } & 8 & 8 & 16(88.9)\end{array}$

Do you make contact with school while child is in school?

$\begin{array}{llll}\text { Daily } & 3 & 0 & 3(16.7) \\ \text { Rarely } & 4 & 3 & 7(38.9) \\ \text { Never } & 1 & 7 & 8(44.4)\end{array}$

Do you manipulate insulin dose to prevent hypoglycaemia in school?

$\begin{array}{llll}\text { Yes } & 4 & 5 & 9(50) \\ \text { No } & 4 & 5 & 9(50)\end{array}$

Are you worried that your child will not get adequate care in school?

\begin{tabular}{llll} 
Yes & 3 & 4 & $7(38.9)$ \\
No & 5 & 6 & $11(61.1)$ \\
\hline
\end{tabular}

with type 1 diabetes mellitus in schools in Nigeria. This report has taken into account the fact that unlike in most developed countries where legislations are available for the responsibility of the school in support of children with various chronic diseases such as diabetes, in most developing countries, these are not available and parents play an important part in ensuring adequate care while their children are in school.

In this report, we found a significant deficiency on the part of parents towards care of their children in school. This was demonstrated by the fact that more than $80 \%$ of parents did not give any plan for care of diabetes or hypoglycaemia and more than $80 \%$ of children did not take glucometers to school. The absence of written plan in management of hypoglycaemia in this study was much higher 
than what was found in a review of management of diabetes in Swedish schools where $40 \%$ of children did not also have written plans for management of hypoglycaemia [11].

Most developing countries have reported challenges with management of children living with Type 1DM and consistently reported poor outcome in these children and youths [5] [6]. Several efforts have been made in improving outcome in childhood diabetes in developing countries, in contrast to what obtains in most developed countries care in school have received poor attention. According to the Swedish Legislation, the National Agency for Education states that the responsibility for supervision is transferred from the parents to the municipality at school [12]. Therefore where such legislation do not exist, the parents remain responsible for enhancing care and supervision at school. The parents therefore have responsibility for arranging appropriate support while their children are in school.

Diabetes care in schools vary greatly between different countries and in distribution of responsibility between parents and school and in regions without legislation, this makes comparison between different regions difficult. In this study, $77 \%$ of parents notified school of child's condition, this is lower than $100 \%$ noted in a study on management of type $1 \mathrm{DM}$ in schools in the UK. In this study, parents notified the school for all children below 10 years. The lower rate of school notification in the older children may be due to the fact that parents feel adolescents have adequate knowledge about diabetes self care and can be independent.

In this study, $56 \%$ of parents reported making contact with school while their children were in school. This is higher than $28 \%$ reported in a Swedish study and is similar to $50 \%$ reported in a Danish study. The rate of contact with school by parents may be dependent on perceived care and support available at school. In Sweden where there is established legislation for support, may account for the lower rate of contact. The fact that parents will have to continue care may enable them keep track of what is happening to their child but account for burnt out syndrome which is common in parents of children living with type $1 \mathrm{DM}$.

Hypoglycaemia is a common problem in children living with type $1 \mathrm{DM}$ even at school. Studies have shown a relationship between parent fear of hypoglycaemia and its consequences including their belief about the child's ability to handle hypoglycaemia [13]. The finding in this study that there was no written plan for management of hypoglycaemia given to the schools and the fact that majority of the students did not take glucometers to school did not support that parents did comprehend the importance of hypoglycaemia and its consequences. However half of the parents adjusted morning dose of insulin to prevent hypoglycaemia in school, this is higher than 25\% reported in a Swedish study and 37\% in Denmark. This adjustment could lead to possible periods of blood glucose fluctuations due to suboptimal insulin with effect on the child's learning ability [14] [15]. Significantly more subjects less than 10 years of age had episodes of hypoglycaemia compared to those older than 10 years, this finding may be due to the 
fact that the older children may be more mature and experienced with managing diabetes and may also have longer duration of diabetes with more experience compared to the younger ones who may still be dependent on parents with their management.

Parent's interest in care of their children in school could depend on the age of the child. In this study, we found that parents were more likely to communicate with school in different aspects of care more for younger children less than 10 years. In contrast however we found that parental worries of care in school were independent of the child's age. There is generally a tendency for support in self care to reduce with age in children living with type 1 DM. In the Swedish study, support in school was highest during the lower grades and reduced in higher grades. In a US study, only $9 \%$ of high school student received support [16]. This may be due to the belief that adolescents are more knowledgeable and can take responsibility for their self care. Although hypoglycaemia occurred significantly more in younger age, other diabetes related problems also occurred in older age and there was no significant difference in $\mathrm{HbAlc}$ between the two age groups indicating need for support in all children with diabetes.

\section{Conclusion}

This study shows that care of children living with type1 DM in school in Port Harcourt, Nigeria is grossly nonexistent. Parents who represent an important link between the health team should be educated on what their role is in ensuring adequate support and care for their wards in school. There is also need for a national regulation on management support in schools for children living with diabetes mellitus to improve outcome.

\section{Acknowledgements}

I will like to thank all parents and children pair who responded to call to participate in this study.

\section{Disclosure}

Author declares no conflict of interest.

This article did not contain any study of human or animal experiments. Informed consent was obtained from all individual participants included in this study.

\section{References}

[1] Patterson, C.C., Dalquist, G.G., Gyurus, E., Green, A. and Soltesz, G. (2009) Incidence Trends for Childhood Type 1 Diabetes in Europe during 1989-2003 and Predicted New Cases 2005-20: A Multicentre Prospective Registration Study. Lancet, 373, 2027-2033. https://doi.org/10.1016/S0140-6736(09)60568-7

[2] United Nations (2008) End Poverty 2015. Fact Sheet on MDG 4. Reduce Child Mortality.

[3] Diabetes Control and Complications Trial Research Group (1994) Effect of Inten- 
sive Diabetes Treatment on the Development and Progression of Long-Term Complications in Adolescents with Insulin-Dependent Diabetes Mellitus: Diabetes Control and Complications Trial. Journal of Pediatrics, 125, 177-188.

https://doi.org/10.1016/S0022-3476(94)70190-3

[4] Nordwall, M., Arnquist, H.J., Bojestig, M. and Ludvigsson, J. (2009) Good Glycaemic Control Remains Crucial in Prevention of Late Diabetic Complications-The Linkoping Diabetes Complications Study. Pediatric Diabetes, 10, 168-176. https://doi.org/10.1111/j.1399-5448.2008.00472.x

[5] Muze, K.C. and Majaliwa, E.S. (2015) Type 1 Diabetes Care Updates; Tanzania. Indian Journal of Endocrinology and Metabolism, 19, S12-S13. https://doi.org/10.4103/2230-8210.155348

[6] Ogle, G.D., Middlehurst, A.C. and Silink, M. (2016) The IDF Life for a Child Programm Index of Diabetes Care for Children and Youth. Pediatric Diabetes, 17, 374-384. https://doi.org/10.1111/pedi.12296

[7] Ogle, G.D., Kim, H., Middlehurst, A.C., Silink, M. and Jenkin, A.J. (2016) Financial Cost for Families of Children with Type 1 DM in Low Income Countries. Diabetic Medicine, 33, 820-826. https://doi.org/10.1111/dme.12997

[8] Wilson, V. and Beskine, D. (2007) Children and Young People with Type 1 Diabetes Mellitus: Managing at School. Journal of Diabetes Nursing, 11, 392-398.

[9] Craig, M.E., Jefferies, C., Dabelea, D., Balde, N., Seth, A. and Donaghue, K.C. (2014) Definition, Epidemiology, Diagnosis and Classification of Diabetes Mellitus. Pediatric Diabetes, 15, 4-17. https://doi.org/10.1111/pedi.12186

[10] Oyedeji, G.A. (1985) Socioecomic and Cultural Background of Hospitalized Children in Ilesha. Nigerian Journal of Paediatrics, 12, 111-117.

[11] Sarnblad, S., Berg, L., Detlofsson, I., Josson, A. and Forsander, G. (2014) Diabetes Management in Swedish School: A National Survey of Attitudes of Parents, Children and Diabetes Teams. Pediatric Diabetes, 15, 550-556. https://doi.org/10.1111/pedi.12133

[12] Skollagen. (SFS 2010:800). Stockholm: The Swedish National Agency for Education.

[13] Gonder-Frederick, L.A., Fisher, C.D., Ritterband, L.M., et al. (2006) Predictors of Fear of Hypoglycaemia in Adolescents with Type 1 Diabetes and Their Parents. Pediatric Diabetes, 7, 215-222. https://doi.org/10.1111/j.1399-5448.2006.00182.x

[14] Perantie, D.C., Lim, A., Wu, J., et al. (2008) Effects of Prior Hypoglycaemia and Hypoglycaemia on Cognition in Children with Type 1 Diabetes Mellitus. Pediatric Diabetes, 9, 87-95. https://doi.org/10.1111/j.1399-5448.2007.00274.x

[15] Parent, K.B., Wodrich, D.L. and Hasan, K.S. (2009) Type 1 Diabetes Mellitus and School: A Comparison of Patients and Healthy Siblings. Pediatric Diabetes, 10, 554-562. https://doi.org/10.1111/j.1399-5448.2009.00532.x

[16] Hellems, M.A. and Clarke, W.L. (2007) Safe at School: A Virgininia Experience. Diabetes Care, 30, 1396-1398. https://doi.org/10.2337/dc07-0121 